\title{
Interfacing between the control ratio of mining excavator and an operator's proficiency level
}

\author{
Vladimir Velikanov ${ }^{1, *}$ Natalja Dyorina $^{1}$, and Ekaterina Rabina ${ }^{1}$ \\ ${ }^{1}$ Nosov Magnitogorsk State Technical University, Magnitogorsk, Russia
}

\begin{abstract}
The role of a mining machine operator gradually reduces to monitoring and managing a technological facility in difficult situations as mining automation increases. The increasing complexity of mining technology leads to the fact that the driver's qualification must be very high in accordance with the requirements of modern mining processes. The main characteristics of the work of the career excavator driver in the «manmachine-environment» system are faultlessness, speed, accuracy, reliability. The effectiveness of the entire system depends on how the human operator's participation will be organized in the process of managing the facility.
\end{abstract}

\section{Introduction}

Active research work related to the qualification of technological personnel in the mining industry has been carried out since the middle of the twentieth century. From the point of view of working out the issue the most significant studies include: «Increasing the productivity of single-bucket excavators» (Dombrovsky N.G., 1951); «Operational reliability and maintenance of ECC (excavator career crawler )-8 and ECC -8I excavators» (Golubev V.A., Trop A.E., Karasev N.M. et al., 1971); «Reliability of mining equipment and the effectiveness of its use» (Golubev V.A., Trop A.E., 1974); «Control modes for SE3 and ECC -4 excavators2 (B. Panev, 1966).

The work indicates that some indicators affecting the high-performance and efficient career excavator operation are not allocated, or their consideration is not paid sufficient attention. These indicators include: non-compliance with the rules of technical operation; low level of design, construction and manufacturing of machines, components and parts; lack of spare parts and their limited supplies; qualification of excavator drivers and repairmen, etc.

The influence of personnel qualifications (excavator drivers) on the management quality of a mining excavator is taken into account in the design dependencies when determining productivity.

In existing methods for determining bottom-hole productivity, mining excavator control modes are evaluated only using the control coefficient $k_{c}$ or $k_{M}$.

The control coefficient $k_{c}, k_{M}$ is recommended to be defined as the ratio of the technical excavator productivity for one hour of good operation to the theoretical productivity, or the

\footnotetext{
* Corresponding author: rizhik 00@mail.ru
} 
ratio of the theoretical duration of the excavation cycle to the actual duration of the cycle under specified operating conditions.

Regarding the influence of the skill level of operators on the excavator management and operation, there is no certain uniformity in approaches, due to the lack of standardized indicators and objective evaluation criteria. As noted in a number of works, the driver's qualification is the potential that lies in it. The basis of qualification is technical education, and as for the classiness it is a formally recognized level of education, the third most important indicator of skill, experience is work term, that is, characteristics of the functional status of the employee.

Modern scientific publications on the impact of driver's qualifications on the mining excavator management quality should be noted (Table 1).

Table 1. Modern approaches in evaluating the management and operation of mining excavators

\begin{tabular}{|c|c|c|}
\hline Author & Scientific concepts & Conclusions \\
\hline $\begin{array}{l}\text { Sharipov R.Kh. } \\
\text { (2011) }\end{array}$ & $\begin{array}{l}\text { The main causes of excavators } \\
\text { handle failure with rack-and- } \\
\text { pinion pressure of the ECC type } \\
\text { are: dynamic loads exceeding } \\
\text { the permissible level; form of } \\
\text { construction leading to a high } \\
\text { concentration of stresses; } \\
\text { consequences of repair actions; } \\
\text { relatively low drivers' } \\
\text { qualification }\end{array}$ & $\begin{array}{l}\text { The laws of the efforts } \\
\text { distribution in the lifting ropes } \\
\text { of excavators of the ECC-5A } \\
\text { type are established when } \\
\text { scooping rock mass depending } \\
\text { on the drivers' length of service }\end{array}$ \\
\hline $\begin{array}{l}\text { Shibanov D.A. } \\
\text { (2015) }\end{array}$ & $\begin{array}{l}\text { The need to increase the } \\
\text { efficiency of the ECC technical } \\
\text { operation, the main direction of } \\
\text { the intervention vector in the } \\
\text { established organization system } \\
\text { of mining operations should be } \\
\text { aimed at qualifying excavator } \\
\text { drivers, observing operating } \\
\text { conditions, as well as creating } \\
\text { conditions for efficient } \\
\text { operation }\end{array}$ & $\begin{array}{l}\text { An algorithm has been } \\
\text { developed for a comprehensive } \\
\text { assessment of the excavator } \\
\text { operating time for the service } \\
\text { life before overhaul. It has been } \\
\text { established that up to } 90 \% \text { of the } \\
\text { impact on the pre-repair } \\
\text { resource reduction is exerted by } \\
\text { three factors: the quality of the } \\
\text { face preparation, the excavator } \\
\text { control and its technical } \\
\text { condition }\end{array}$ \\
\hline
\end{tabular}

\section{Methodology}

In the study of complex technical systems, in most cases there are dependencies between variables when each value of a variable corresponds not to certain, but to the set of possible values of another variable. In other words, each value of a given variable corresponds to a certain (conditional) distribution of another variable. This dependence is called statistical [1-5].

The concept emergence of statistical relationship is caused by the fact that the dependent variable is subject to the influence of a number of uncontrollable factors, as well as the fact that the measurement of the variables values is inevitably accompanied by some random errors.

We propose to take into account the level of technical competence of operators, characterized by a coefficient of efficiency $\mathrm{k}_{\mathrm{ef}}$, determined by education, work experience, as well as the ability to master and operate mining equipment of any degree of complexity and autonomy. 
The establishment of a close connection between the controllability of the excavator (control coefficient) and the coefficient of efficiency of the excavator driver is of practical interest. The excavator control coefficient $\mathrm{k}_{\mathrm{c}}$, established taking into account only the length of the excavation cycle, characterizes the quality of the excavator control is not completely. Consider the statistical relationship between the control coefficient of the excavator $k_{c}$, i.e. coefficient taking into account the experience and practical skills of the excavator driver and the efficiency coefficient of the excavator driver.

In order to establish the presence or absence of such a relationship, we used one of the statistical methods, namely, correlation analysis.

At first glance, the regression coefficient is a suitable measure of the relationship tightness between one quantity and another, because it shows how many units on average one quantity changes when another quantity increases (decreases) by one unit.

However, the regression coefficient depends on the units of variables measurement. We consider dimensionless quantities (control coefficient and ranking coefficient), for the indicator of communication tightness we need a standard system of units of measurement in which data on various characteristics would be comparable among themselves. Such a quantity is the quantity $r$ - a sample correlation coefficient (or simply a correlation coefficient), since it is a dimensionless indicator of the tightness of the connection between two or more values. We note the main properties of the correlation coefficient (for a sufficiently large sample size $n$ ):

1. The correlation coefficient takes values on the interval $[-1,1]$. Depending on how $|r|$ approaches 1, they distinguish between a weak, moderate, noticeable, fairly close, close and very close relationship, i.e. the closer $|r|$ to 1 , the closer the connection.

2. If all the values of the variables are increased (decreased) by the same number or by the same number of times, then the value of the correlation coefficient will not change.

3. For $r= \pm 1$, the correlation is a linear functional relationship. In this case, the regression lines coincide for both signs and all observed values are located on a common line.

4. At $r=0$, there is no linear correlation. In this case, the group means of the variables coincide with their common means, and the regression lines are parallel to the coordinate axes. However, the absence of linear correlation dependence does not mean that any correlation dependence is completely absent.

5. The sign of the correlation coefficient determines the direction of influence of one sign on another, i.e. the connection is direct if it is positive, and the reverse if it is negative. The correlation coefficient module determines the strength of the bond. It is generally accepted that if $0,7 \leq|r| \leq 1$, then the relationship is close between random variables; $0,5 \leq|r| \leq 0,7$ average relationship; $0 \leq|r| \leq 0,5$ - the relationship between random variables is weak.

In order to calculate the correlation coefficient, we used the following formula:

$$
r=\frac{\sum_{i=1}^{n}\left(x_{i}-\bar{x}\right)\left(y_{i}-\bar{y}\right)}{n \sigma(x) \sigma(y)}
$$

where $x_{i}, y_{i}$-respectively the control coefficient and the efficiency coefficient of the excavator driver; 
$\bar{x}, \bar{y}$ - arithmetic mean values of the control coefficient and the efficiency coefficient of the excavator driver;

$\sigma(x), \sigma(y)$ - standard deviations of the control coefficient and the efficiency coefficient of the excavator driver.

The arithmetic mean values of the control coefficient and the efficiency coefficient of the excavator driver were calculated using the formulas:

$$
\bar{x}=\frac{\sum_{i=1}^{n} x_{i}}{n}, \bar{y}=\frac{\sum_{i=1}^{n} y_{i}}{n}
$$

The standard deviations of the control coefficient and the efficiency coefficient of the excavator driver were calculated using the formulas:

$$
\sigma(x)=\sqrt{\frac{\sum_{i=1}^{n}\left(x_{i}-\bar{x}\right)^{2}}{n}}, \sigma(y)=\sqrt{\frac{\sum_{i=1}^{n}\left(y_{i}-\bar{y}\right)^{2}}{n}}
$$

\section{Results}

The total sample size for experimental testing was $n=381$ excavator drivers. The base enterprise of the experiment, PJSC Magnitogorsk Iron and Steel Works, was investigated: a mine - 168 people, a central industrial school - 131 people, a central laboratory - 61 people, and a mining department - 21 people mining and processing industry (MPI).

The minimum control coefficient for all drivers of the excavator was 0.56 , and the maximum was 0.95 . The minimum coefficient of efficiency of the excavator driver as a result of the study was identified -0.35 , the maximum - 0.85. Using formulas (2) and (3), the arithmetic mean values of the control coefficient and the efficiency coefficient of the excavator driver were calculated, as well as the standard deviations of the control coefficient and the efficiency coefficient of the excavator driver. The obtained data were substituted into formula (1), by which the correlation coefficient was calculated. The resulting value was 0.97 , which indicates a very close relationship between the control coefficient and the efficiency coefficient of the excavator driver [6-9].

In addition to the fact that we have established the existence of a relationship between the two considered parameters, we can also assess how significant the correlation coefficient is. A significance check of the correlation coefficient was carried out by Student's criterion:

$$
t=\frac{|r| \sqrt{n-2}}{\sqrt{1-r^{2}}}
$$

where $n$ is the sample size (381 excavator drivers), $r$ is the correlation coefficient (0.97).

In the calculation, the obtained $t$-test is compared with the tabular (critical) value of $t_{c r}[10,11]$.

If $t>t_{c r}$ then the correlation coefficient is significant, therefore, there is a relationship between random variables. As a result, we obtained $t=75.66$, and $t_{c r}$ with these parameters is 32.33 , which is significantly less than the calculated $t$, therefore, there is a 
relationship between the controllability coefficient and the efficiency coefficient of the excavator driver, which does not contradict the assumption made.

Figure 1 presents the study's results of the efficiency factor impact of the excavator driver on the face performance of mining excavators.

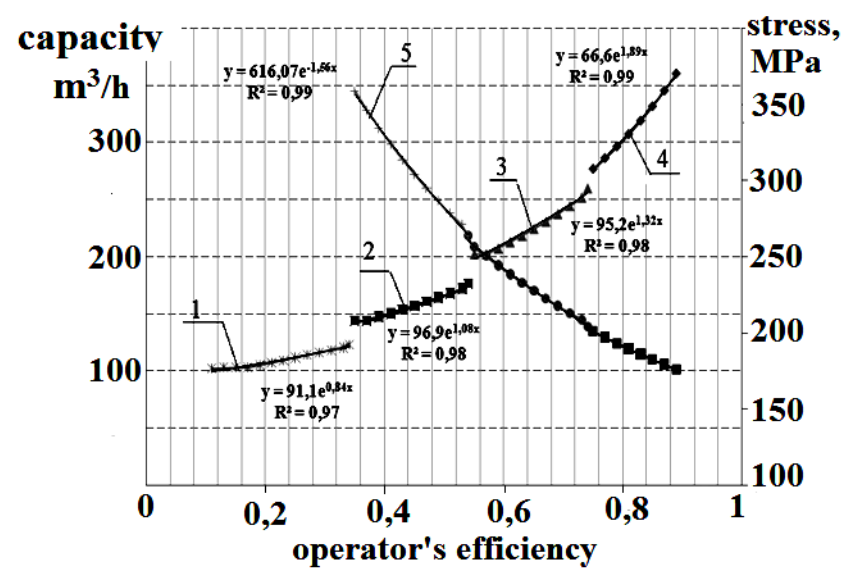

Fig. 1. Dependence of face productivity on efficiency coefficient: 1- experience less than a year; 2 - experience 1-5 years; 3- 5-10 years of experience; 4 - experience of 10-15 years or more; 5 - dependence of the stress in the handle on the control coefficient

\section{Conclusion}

The obtained results can be used in the design of new and modernization of existing models of excavators to increase their competitiveness and achieve optimal performance during operation and increase the operational reliability of mining machines.

\section{References}

1. Yu. Fokin, Technical equipment operator: ensuring reliability (Military Publishing House, Moscow, 1985)

2. A. Gubinsky, Reliability and quality of functioning of ergatic systems ("Science", Leningrad, 1982)

3. D. Miller, A. Swain, Human factor. 1(1991)

4. V. Scheblanov, A. Bobrov, Psychological journal. 3 (1990)

5. E.Woodson, Human factors design handbook (McGraw-Hill, New York, 1981)

6. V. Velikanov, N. Dyorina, A. Abdrakhmanov, Matec web of conferences, 129 (2017)

7. V. Velikanov, E. Ilina, N. Dyorina, Procedia Engineering. 150 (2016)

8. V. Velikanov, A. Kozyr, N. Dyorina, Procedia Engineering. 206 (2017)

9. V. Velikanov, I. Usov, A. Abdrakhmanov, I.I. Usov, Mining Journal. 12 (2017)

10. J. Bendat, A. Piersol, Applied random data analysis (Mir, Moscow, 1989)

11. N. Kremer, Probability Theory and Mathematical Statistics. (2003) 